\title{
Guerra y cultura histórica a finales del periodo colonial. El culto al conquistador Hernán Cortés entre el ejército borbónico ${ }^{1}$
}

\author{
Nuria Soriano Muñoz ${ }^{2}$
}

Recibido: 25 de marzo de 2018 / Aceptado: 29 de enero de 2019

Resumen. Este artículo pretende analizar la importancia política y cultural que tuvo Hernán Cortés entre las filas del ejército borbónico. Mi objetivo es profundizar en los pilares que sustentan la memoria cultural del conquistador de México, sus valores, significados y popularidad histórica en la segunda mitad del siglo XVIII e inicios del siglo XIX. Para ello, se abordará la literatura producida al calor de la controversia sobre el "Nuevo Mundo," especialmente apologías, manuales, diarios y poemas en los que el polémico personaje es defendido de las acusaciones de crueldad y barbarie. Sus acciones de conquista se recuerdan con orgullo y nostalgia en un contexto de prolongados conflictos bélicos y de notable incremento de la literatura militar. La memoria encomiástica de Hernán Cortés, producida por hombres de armas como Antonio de Alcedo (1734-1812), José de Cadalso (1741-1782), Francisco Saavedra (1746-1819), Gaspar María de Nava (1760-1815), Dionisio Alcalá Galiano (1760-1805) y José Vargas Ponce (1760-1821), se entiende como rasgo compartido y mecanismo de solidaridad entre una milicia que contribuyó intensamente a la construcción del perfil histórico de Cortés. Esta reivindicación del personaje debe comprenderse, en definitiva, como una pequeña pieza de un proceso más amplio de heroización que recorre la cultura de finales de siglo. En último término, el elogio del conquistador extremeño se pondrá en relación con la propia identidad socioprofesional del ejército, la idea de la guerra y la construcción de una cultura histórica común.

Palabras clave: Ejército; guerra; cultura histórica; memoria cultural; Hernán Cortés; Ilustración; siglos XVIII-XIX.

\section{[en] War and the Culture of History at the End of the Colonial Period. The cult to Hernan Cortes among the Bourbon armies}

\begin{abstract}
This article attempts to analyse the political and cultural importance of Hernan Cortes within the ranks of the Bourbon armies. My objective is to delve into the pillars that have sustained the cultural memory of the conqueror of Mexico - his values, significance and historical popularity in the second half of the 18th and beginning of the 19th century. To that end we have addressed the literature produced in the heat of the controversy over the "New World", especially apologies, manuals, diaries and poems that defend the controversial figure from accusations of cruelty and barbarism. His actions during the conquest are evoked with pride and nostalgia within the context of prolonged wars and a

1 Este artículo se inscribe en el marco del proyecto "Construcciones del yo: narraciones y representaciones del sujeto moderno entre lo personal y lo colectivo: Siglos XVII-XIX" con referencia HAR2014-53802-P. Los resultados del mismo han contado con la financiación de la Generalitat Valenciana y del Fondo Social Europeo, gracias a una ayuda para investigadores en fase postdoctoral concedida por la Conselleria d'Educació, Investigació, Cultura i Esport. Agradezco los comentarios del Dr. Juan Francisco Pardo Molero (Universitat de València), de los que se ha beneficiado notablemente este texto.

2 Departament d'Història Moderna i Contemporània, Universitat de València.

E-mail: nuria.soriano@uv.es
\end{abstract}


notable increase in military literature. The praiseful memory of Hernan Cortes, produced by men of arms such as Antonio de Alcedo (1734-1812), Jose de Cadalso (1741-1782), Francisco Saavedra (17461819), Gaspar Maria de Nava (1760-1815), Dionisio Alcala Galiano (1760-1805) and Jose Vargas Ponce (1760-1821) is interpreted as a shared trait and mechanism of solidarity among militiamen that contributed significantly to the construction of the historical profile of Cortes. This acclaim of the figure should definitively be understood as a small piece within a much larger process of heroization that marks the culture of the fin de siècle. Lastly, the praise of the conqueror from Extremadura is assessed in relation to the socioprofessional identity of the army, the idea of War and the construction of a common historical culture.

Keywords: Army; War; Historical culture; Cultural memory; Hernán Cortés; Enlightenment; 18-19 Centuries.

Sumario. 1. Introducción: La alargada sombra de Hernán Cortés. 2. Guerra e Ilustración: Los contextos. 3. Una afinidad común: Hernán Cortés en la literatura primaria. 4. Reflexiones finales. 5. Referencias bibliográficas.

Cómo citar: Soriano Muñoz, N. (2019) Guerra y cultura histórica a finales del periodo colonial. El culto al conquistador Hernán Cortés entre el ejército borbónico, en Revista Complutense de Historia de América 45, 239-260.

\section{Introducción: La alargada sombra de Hernán Cortés}

Por mediación de su compatriota Ricardo Wall, William Bowles se dirige a la Península Ibérica con la intención de supervisar algunas explotaciones mineras y establecer un gabinete de historia natural. Mientras viajaba, decide escribir unas impresiones que años más tarde, en 1782, divulgará con éxito. Encamina sus pasos hacia Extremadura y se dirige a Medellín. El naturalista irlandés avista entonces la casa natalicia de Hernán Cortés. Según recoge en su Historia Natural, los lugareños insistían en que se trataba de una morada muy digna de memoria y veneración, un espacio en el que todavía se proyectaba la alargada sombra de Hernán Cortés. Aquella humilde casa formaba parte del itinerario mítico que se había ido forjando sobre el recuerdo de aquel conquistador. La Introducción a la historia natural y geografía física de España de William Bowles constituye una prueba evidente de la popularidad del conquistador extremeño en el siglo XVIII'.

Precisamente durante aquellos años en los que se publicaba la obra de Bowles, Hernán Cortés revivió con fuerza en una amplia y bien diversa gama de productos literarios que, además, iría creciendo en comparación a lo sucedido durante las décadas anteriores de la centuria ${ }^{4}$. Este incremento se vio favorecido, entre otras razones, por la reedición de la crónica del historiador y dramaturgo madrileño Antonio de Solís, publicada originalmente en 1684 y reimpresa, al menos, en quince ocasiones a lo largo de todo el siglo. Precisamente la crónica de Antonio de Solís -y no parece casualidad que el polígrafo fuera incluido en la Galería de Españoles Ilustres aus-

Bowles, 1782: 161-162.

$4 \quad$ El mayor auge de la producción cortesiana se produce en el año 1770 y se mantiene al alza hasta la entrada del s. XIX, incrementándose de nuevo en 1780 gracias a la circulación de artículos de prensa, literatura épica, apologías y obras teatrales que vindicaban al personaje como respuesta a las críticas que muchos ilustrados habían escrito contra la actuación de España en América. Algunos ejemplos en: Fabbri, 1980; Gies, 2009; Hernández, 2012: 151-152; Morales, 2008; Rubial García, 2010. 
piciada por Floridablanca- era un texto que celebraba la valentía de Hernán Cortés y su valor como gran general, así como su conocimiento y prudencia en el ejercicio del arte militar. Si se repara con atención en la conducta que, desde el principio hasta el final, mostró Cortés -afirmaba Solís- apenas podrá hallarse otro en la Antigüedad que le hiciera sombra 5 .

Además de las reediciones de Solís -y algunas otras, como la de Bernal Díaz del Castillo, que volvería a publicarse en 1795- la cultura de la segunda mitad del siglo XVIII estuvo marcada por la polémica intelectual sobre el carácter y la historia del "Nuevo Mundo". Mientras América se convertía en el foco de atención en los debates y la prensa cosmopolita y patriótica, las críticas contra España por su actuación en la conquista y colonización arreciaban. Años después de las traducciones del duque de Almodóvar y de la publicación de la obra de Muñoz - encargado de redactar una historia de América alternativa a la de Robertson, más afín a los intereses de la monarquía - una nueva edición de Solís vio la luz en 1783 en la imprenta de Antonio de Sancha. Acompañada por un grabado de Fernando de Selma, en el primer volumen podía contemplarse la figura de Cortés, acompañado por un medallón ovalado que enmarcaba su imagen, en el que aparecía una bandeja de plata sobre la que descansaban un casco guerrero y unas ramas de laurel, símbolos de la gloria imperecedera, de la grandeza y el triunfo de las armas. El carácter militar de Hernán Cortés era resaltado en una obra que venía a engrandecer el prestigio y la reputación del extremeño entre los hombres y las mujeres de la Ilustración, especialmente entre los militares, muchos de ellos comprometidos con los valores de la patria, la defensa de España y su pasado.

La figura de Hernán Cortés alcanzó gran visibilidad en el contexto ilustrado de la polémica americana. Muchos literatos entendieron al conquistador como modelo a imitar, una figura heroica y singular que descollaba mientras España, precisamente, no gozaba de buena prensa internacional. Las críticas hacia la obra de la monarquía en América fueron generando cierta conciencia de nación "atacada" y "ofendida" por los extranjeros ${ }^{6}$. En este sentido, los militares no perdieron la oportunidad de reivindicar el sistema colonial español, a los "héroes" de la conquista de América, y especialmente a Cortés. Usando la pluma legitimaron el poder de España en las "Indias", con la intención de que no pasaran al olvido las acciones que, a su juicio, el conquistador de Medellín había emprendido en aquella "inhóspita" e "incivilizada" América.

\section{Guerra e Ilustración: Los contextos}

Generalmente, la guerra y los fenómenos de conquista, tan vinculados a la imagen del propio Hernán Cortés, han sido sinónimo de horror, agonía y muerte. Para los hombres del siglo XVIII constituyó una experiencia cotidiana, recurrente y dramática. Feroz y sangrienta, la guerra truncaba las vidas anónimas de los súbditos y provocaba la ruina de las monarquías. Pese a las complejas y variables causas que motivaban los conflictos bélicos, solía ser un modo habitual de engrandecer los te-

\footnotetext{
5 Solis, 1783: 6. En su prólogo afirmaba que la empresa americana había durado "sin perder la novedad en la memoria de los hombres".

6 Checa Beltrán, 2012.
} 
rritorios del estado, consolidar su poder político y económico, y expandir la religión católica. Las guerras de conquista del "Nuevo Mundo" eran un buen ejemplo de ello.

Las disputas armadas y los conflictos bélicos suponían gastos cuantiosos y causaban daños irreparables. Sus secuelas eran marcadamente destructivas ${ }^{7}$. El ilustrado Juan Pablo Forner contemplaba las cosas de este modo. Cuando todavía la Guerra de la Convención no había tocado a su fin, se refirió a ella como "el más atroz de los males" compuesto por uno de los miembros de la Sociedad de Amigos del País de Madrid pudo dejar de referirse a la guerra como la "enfermedad más extraordinaria de los estados" . La guerra, sin embargo, no siempre fue denostada ${ }^{10}$. Una milicia excelente y un arsenal moderno fueron considerados como la mayor garantía de la paz y de la estabilidad. Si vis pacem, para bellum. Bajo determinadas circunstancias, pues, la guerra y la milicia podían convertirse en escuela de lo más conveniente, justo y santo $^{11}$. La guerra podía ser considerada entonces como el escenario propicio de la modernidad: como un espacio en el que prevalecían los mitos del progreso, del hombre y la nación. Por espacio de ocho siglos, los españoles no habían pensado en otra cosa que en las armas. De tal modo se expresaba el hijo del marqués de Llanos, el ilustrado José de Olmeda y León (1740-1805) una de las figuras peor conocidas de la Ilustración tardía ${ }^{12}$.

La literatura sobre hechos de armas, el heroísmo de los soldados y sus acciones de conquista solía adoptar, por lo común, la forma de elogios funerarios, poemas épicos, pinturas, diarios, apologías y sermones. Durante los últimos momentos del siglo XVIII y primeros años del siglo XIX su presencia en el panorama editorial español había ido in crescendo. Esta escritura subrayaba precisamente la importancia de aquellas figuras del pasado que habían alcanzado la fama gracias a su profesión militar y se constataba, por añadidura, que el carácter guerrero era uno de los rasgos distintivos de los españoles como pueblo, tal y como había señalado el propio José de Olmeda. Desde luego, no cabe duda de que la idea de conquista, adaptada ahora a los ideales ilustrados, siempre fue uno de los motores que hicieron funcionar a la monarquía y a la propia representación del pasado que se construyó al calor de este concepto.

Morir y matar en la guerra no sólo era una circunstancia habitual, más o menos asumida por sus potenciales actores, una prueba de sacrificio, un episodio dramático más en la larga y dura lucha contra los enemigos, y uno de los resortes que hacía funcionar el aparato político, sino también un índice que permitía diferenciar el grado de grandeza y civilización de la sociedad, por ejemplo, a la hora de comparar el mundo europeo y el no europeo. La guerra albergaba en sí los ingredientes adecuados para conformar cierto sentimiento nacional, de diferenciación y forja de estereotipos.

La relevancia de las ideas de honor y valentía, tan presentes en aquel "noble arte militar", la lucha por el rey, el catolicismo y la patria -con todas las complejidades semánticas del concepto en la época-cobraban cuerpo a través de representaciones

\footnotetext{
En ello ya había insistido el pensamiento humanista del Renacimiento. Véase Fernández Santamaría, 1988.

Forner, 1794: 19.

Martínez de Hervás, 1795: 5.

García Hernán - Maffi, 2006.

Lavenia, 2014a: 328-352. Lavenia, 2014b.

12 La publicación salió a la luz coincidiendo con la década en la que se incrementan los textos sobre Hernán Cortés. Olmeda y León, 1771: 7.
} 
culturales y se articulaban alrededor de imágenes como la del conquistador militar -que asoma por todas partes-y del soldado victorioso en la memoria viva de batallas del pasado. Estas imágenes poseían el poder de incentivar el reclutamiento de los hombres y de aprontar recursos para la guerra, una preocupación siempre viva para los responsables del gobierno de la monarquía. Conviene apuntar en este sentido que el "Siglo de las Luces" se impregnó de todo tipo de modelos de exaltación de la figura del soldado-héroe muerto por la patria, compuestos en un tono vibrante y altamente emotivo.

No obstante, encontramos algunas novedades particulares y propias del "Siglo de las Luces" en lo que se refiere al mundo de la guerra y la milicia. Pueden resaltarse un par de aspectos que deberán ser tomados en consideración para contextualizar las fuentes con una precisión mayor. En primer lugar, y como ha analizado Manuel Reyes García Hurtado, la estrecha y específica relación que los militares a lo largo de la Ilustración mantuvieron con el mundo del libro, la imprenta, la cultura escrita y la ciencia. Aunque pudiera pensarse lo contrario, muchos de los militares no buscaban con su actividad literaria el éxito editorial, sino más bien el servicio a la Corona y a sus compañeros de $\operatorname{armas}^{13}$. Sus textos podían traducirse en méritos que les permitían acceder a gratificaciones o ascensos, reforzar su moral y sus convicciones, e, incluso, debilitar el estado de ánimo del enemigo.

En segundo lugar, muchas de las obras que integraban la esfera militar -donde la influencia de la Iglesia era, como ya en muchas ocasiones se ha subrayado, muy acusada-cabe analizarlas en consonancia con el surgimiento de las academias militares, las reformas políticas y los tratados que proliferaron tanto en el extranjero como en la Península y que, de alguna manera, impulsaban a dejar constancia de los adelantos de la ciencia de la guerra en todos sus aspectos.

Es cierto que durante el siglo XVIII tuvo lugar un marcado crecimiento de las publicaciones relacionadas con el mundo militar, en consonancia con el incremento de las reformas destinadas a mejorar la disciplina, la eficacia y la formación del ejército $^{14}$. Por lo que se refiere a las publicaciones, cabría subrayar que el incremento de la producción impresa de carácter militar a partir de la década de los años setenta supone cierta eclosión que se halla en consonancia con el auge de las reivindicaciones apologéticas de la figura de Hernán Cortés desde la literatura, la prensa e incluso la iconografía. La frustrada invasión de Argel (1775 y 1783), la conquista de Menorca (1782), el fracasado sitio de Gibraltar (1779-1783), la Guerra contra la Convención (1793-1795), los combates navales del Cabo Espartel (1782) contra Reino Unido y la Batalla de Trafalgar (1805) son sólo algunos ejemplos de esa intensidad dramática, por mar y tierra, de años de persecuciones y pérdidas humanas, del sonido de los cañones y de las campañas de propaganda, pero también de oportunidades para vincular el pasado y el presente a través de los antepasados.

La literatura que se produjo al calor de estos conflictos permite comprobar que la imagen del soldado del "Siglo de Oro" no se había desvanecido". Era esta una personificación entretejida con tópicos variados como el del guerrero católico, de profunda moral y acendrada ortodoxia, resuelto a cumplir con sus deberes cristianos, personificación de una idea y de unos ideales de cruzada que todavía seguían muy

\footnotetext{
García Hurtado, 2002: 124.

Andújar, 1991.

García Hernán, 2006.
} 
vivos: la imagen -en definitiva- de un soldado obligado a cultivar todas las virtudes castrenses, desde el valor y la disciplina hasta el amor y el sacrificio por la patria, valores que Hernán Cortés representaba a la perfección. Las dificultades de esta profesión, como es sabido, precisaban de todo tipo de refuerzos morales e incentivos. Y, cuando de esto se trata, la mejor opción la encontramos en el culto al pasado.

El lector puede preguntarse, acertadamente, cómo dieron sentido a sus acciones y pensamientos los individuos que participaron en las diferentes contiendas bélicas del siglo, algunos de los elementos que les permitían posicionarse de una manera o de otra, cómo se construían sus imaginarios y referentes. ¿Les llevó Hernán Cortés, quizá, más de doscientos sesenta años después de su muerte, hacia alguna dirección? ¿Se apoyaron en su ejemplo para tomar alguna decisión, movilizarse y dar sentido a la guerra? El abanico de los textos que veremos en el siguiente apartado nos aproxima a las trayectorias personales de unos hombres comprometidos con la vida militar, formados, en virtud de las exigencias de su oficio, en lenguas, matemáticas y geografía, y que incluso llegaron a solicitar personalmente participar en determinadas campañas bélicas, como fue el caso de Vargas Ponce o José de Cadalso ${ }^{16}$. Su escritura se consagró en no pocas ocasiones a la defensa del honor nacional, de la historia y de la lengua española, dentro de esa corriente apologética imprescindible para comprender la cultura política de la segunda mitad del siglo, en la que América resultó un elemento capital.

\section{Una afinidad en común: Hernán Cortés en la literatura primaria}

Los testimonios de finales de siglo que promovieron el recuerdo y singularizaron la dimensión militar de Hernán Cortés, sus exitosas batallas y hazañas épicas son muy numerosos. Muchos de los escritores que avivaron la llama de su memoria desempeñaron algún tipo de cargo militar a lo largo de sus trayectorias personales o defendieron los valores bélicos estrechamente ligados a la cultura española. La gran mayoría, en definitiva, había seguido la típica carrera de letras en las instituciones regias, en aquellos espacios en los que se fueron gestando las respuestas patrias a las incómodas críticas extranjeras ${ }^{17}$. José de Olmeda fue uno de los intelectuales que, en el contexto del que nos ocupamos, impregnó sus escritos de un marcado tono apologético. Su obra, titulada Elementos del derecho público, se había publicado en $1771^{18}$. El texto constituía un magnífico exponente de la cultura jurídica del momento. Ciertamente, nos hallamos ante un panegírico sobre el honor y el valor de los guerreros que habían dado gloria a la nación española, lo cual no era óbice, sin embargo, para que Olmeda fuera perfectamente consciente de lo efímeras que habían sido aquellas grandes victorias del pasado.

Olmeda había nacido en el seno de una familia de notoria nobleza. Estudiante de jurisprudencia, había sido instruido en el Real Seminario de Nobles de Madrid ${ }^{19}$. Había entablado amistad con el coronel y literato José de Cadalso. Además de ser miembro de la Real Sociedad Económica de la capital y de haber ascendido al puesto

\footnotetext{
García Hurtado, 2002: 232.

Mestre, 2003.

Olmeda y León, 1771.

Herrero Rubio, 1947.
} 
de oficial de la Audiencia Real de Sevilla, Olmeda había desempeñado el cargo de Alcalde de Casa y Corte. A Olmeda le interesaban los sentimientos conexos al honor, a la patria y al culto a los antepasados. Conocía bien las maravillosas glorias que algunos "fuertes varones" habían producido "blandiendo sus cuchillos" 20 . Actitudes y defectos morales como la cobardía, la flaqueza y la feminidad se oponían -en su opinión- a la guerra entendida como un acto político. En su texto incluía, además, un resumen de las principales acciones militares que habían ilustrado a la nación, haciéndola gloriosa en todo el orbe. Aquellas batallas eran más bien un índice de su espíritu y carácter, del honor de una nación que se convertía, para Olmeda, en materia de Estado. Consideraba también que, si una nación podía llamarse guerrera, era una injusticia disputarle a España la gloria de este epíteto. El prolífico escritor dirigía su mirada hacia el pasado, donde Numancia, Guadalete, Covadonga y Lepanto eran las pruebas más fehacientes del valor y el ardimiento español. Su recuerdo permitía justificar su postura política. Los ejemplos no eran pocos y, entre ellos, señalaba, por un lado, la batalla de Otumba, ganada por Hernán Cortés a más de doscientos mil mexicanos y, por otro, la de Cajamarca, en la que Pizarro venció a cuatro mil indios $^{21}$.

Planteamientos semejantes a los de Olmeda los hubo -y no pocos- en el siglo XVIII, pero no fueron expresados ni de la misma forma, ni con el mismo tono, ni con el mismo grado de patriotismo por todos los autores. Antonio de Alcedo (17341812) fue uno de aquellos militares con conocimientos científicos -en particular, de geografía- que, por descontado, no ignoraba quién había sido el conquistador de México. Nacido en Quito en el seno de una distinguida familia criolla, su padre había disfrutado de importantes cargos políticos, entre ellos, la presidencia de la Audiencia de Panamá en las primeras décadas del siglo XVIII. El joven Alcedo ocupó el cargo de gobernador político y militar de Alzira, después en Valencia y La Coruña, donde vivió la ocupación francesa ${ }^{22}$. A lo largo de su rápida carrera de armas -alcanzó el grado de mariscal de campo- encontró el tiempo suficiente para componer un extenso diccionario enciclopédico, el célebre Diccionario Geográfico de Indias Occidentales, publicado en cinco volúmenes editados entre los años 1786 y 1789.

Este texto -también traducido al inglés-constituye una prueba excelente del incremento que las obras de naturaleza geográfica alcanzaron durante la centuria. A lo largo de sus páginas se recogen datos muy heterogéneos sobre geografía, física, zoología o hidrografía, de marcado interés para Europa tanto desde el punto de vista comercial como político. Los objetivos de Alcedo en la composición de su texto fueron bien diferentes de los de Olmeda. Sin embargo, ambos compartían la opinión de que el marqués de Oaxaca merecía la celebridad de la que gozaba, puesto que había sido un hombre insigne y valeroso.

Hernán Cortés aparece dispersa y tímidamente en el texto como el conquistador que agregó el territorio mexicano a los dominios de la monarquía española. En ocasiones, el autor se refiere al conquistador como "famoso"23. También lo califica de

20 Olmeda y León, 1783: 10. Así lo aseguró en el discurso realizado en la Real Sociedad de Madrid en 1783. Entre los asistentes, se encontraban corregidores y síndicos de la ciudad, párrocos y vicarios, y entre ellos, el arzobispo de Toledo, Francisco Antonio Lorenzana, que pagó de su propio bolsillo la impresión de la obra. Unos años antes, este religioso se había encargado de editar en México la conocida Historia de la Nueva España.

21 Olmeda y León, 1771: 279.

22 Hidalgo Nuchera, 1998: 185. Sobre el principal texto de Alcedo puede consultarse también Lerner, 1971: 71-93.

23 Alcedo, 1789: 78 . 
"incomparable", y añade que "conquistó el imperio de los mexicanos [...] el año de 1521, siendo casi un milagro que, con poco más de 300 españoles, sujetase tantos millones de hombres, cuyo patriotismo pudo competir con el de los romanos" ${ }^{24}$. Lo sucedido durante la conquista de aquel territorio se encontraba a medio camino entre lo terrenal y lo milagroso. El teatro de la guerra -en su opinión- era el escenario más apropiado para las acciones heroicas: el lugar en el que podía desplegarse el valor acreditado por la conducta y la pericia militar. Las guerras eran ciertamente sangrientas, pero, al mismo tiempo, podían resultar útiles. Desde luego, las que se habían desarrollado en el "Nuevo Mundo" habían servido para reducir el número de esclavos y de indios que morían a manos de los pueblos indígenas más belicosos. La guerra prolongada en el tiempo constituía también un elemento para diferenciar a los indios salvajes de los más pacíficos, así como un índice francamente valioso para distinguir a los pueblos más valerosos ${ }^{25}$.

Ignoramos si el poeta y escritor valenciano León de Arroyal (1755-1813) conoció a Antonio de Alcedo. Sabemos, por el contrario, que Arroyal frecuentaba la tertulia de Cadalso. Mantuvo relación con el escritor Juan Pablo Forner, por entonces estudiante de la Universidad de Salamanca, y con algunos otros compañeros de aula. Más allá de compartir una misma tertulia literaria, existían entre ellos algunas otras afinidades. Aunque estimaba la guerra un trastorno terrible y cruento, Forner consideraba a Hernán Cortés un héroe y excelente militar, con una perfección avalada por sus acciones en diversos sitios, batallas y retiradas ${ }^{26}$. El marqués de Oaxaca era, en pocas palabras, la viva imagen del genio y del triunfo bélico.

León de Arroyal también contribuyó a la construcción del perfil individual del conquistador. Este hijo de abogados conocía bien el sistema hacendístico y fiscal español. Traductor y aficionado a la sátira, Arroyal mantuvo correspondencia con algunas de las principales figuras políticas de su época, como Francisco de Saavedra, hombre cercano a Jovellanos y ministro de Hacienda con el gobierno de Godoy. En 1784 Antonio de Sancha dio a las prensas un conjunto de creaciones literarias en verso, compuestas por el autor de Pan y toros. Las odas que formaban parte de este impreso eran de temática muy variada, de carácter histórico, político y personal.

Entre ellas, destacaremos la oda número treinta y tres: un texto laudatorio en el que vindicaba al mariscal de campo, marino y almirante de la Real Armada española, don Antonio Barceló (1717-1797). La oda, escrita en el año 1781, recordaba al militar mallorquín que había participado -junto al duque de Osuna, Pedro de Alcántaraen las sucesivas aventuras militares que emprendió en Argel Alejandro de O'Reilly y en los sitios de Gibraltar ordenados por Carlos III entre 1779 y $1783^{27}$. Barceló también había sido objeto de la atención literaria de Vicente García de la Huerta. Arroyal, sin embargo, había introducido un matiz digno de mención: la capacidad de conmover y de encaminar el ánimo hacia la realización de acciones valerosas de los grandes militares de todos los tiempos ${ }^{28}$. Para mejor ensalzar la figura del marino Antonio Barceló, Arroyal graduó sus gestas con las protagonizadas por otros grandes hombres, especialmente por Hernán Cortés, lo cual - debió pensar- contribuiría a fijar en la memoria el recuerdo de sus acciones.

\footnotetext{
Ibídem: 466.

Ibídem: 81.

Forner, 1787: 159.

Chávez, 2001.

Arroyal, 1784: 104.
} 
León de Arroyal y José de Cadalso (1741-1782), en efecto, mantuvieron relación. El coronel gaditano también llegó a conocer al escritor José de Olmeda. Su encuentro fue posible gracias a la mediación de su hermano, con el que había coincidido en el Real Seminario de Nobles madrileño. El famoso coronel de caballería y literato participó en el asedio de Gibraltar, donde perdió la vida. Sus desavenencias con la censura fueron más que notorias, pues no pudo ver publicada completamente una de sus principales obras: las Cartas Marruecas. Sin duda, Cadalso es uno de los hombres más representativos de la Ilustración española. La bibliografía dedicada al autor de Los eruditos a la violeta es, como se sabe, bastante extensa ${ }^{29}$. Las Cartas Marruecas era una obra compuesta por noventa epístolas, escritas en diferentes momentos de su vida, aunque las más primitivas podrían fecharse a finales de la década de los sesenta. Tradicionalmente se ha venido subrayando la conexión de las Cartas Marruecas con las Cartas Persas de Montesquieu. Su contenido ha sido considerado un ejercicio de crítica social, aunque también se ha entendido como parte de "una tradición epistolar muy difundida en la Europa de aquel momento" ${ }^{\text {"30 }}$. Una primera edición se realizó por entregas en el Correo de Madrid, en una versión que contiene notables modificaciones respecto al texto que imprimiría después Antonio de Sancha.

El tono de la carta IX -bien conocida por la historiografía- es marcadamente apologético. En ella, el escritor - nostálgico de la grandeza de su patria- alababa la actuación de los conquistadores de América, al mismo tiempo que criticaba a aquellos "otros" europeos que se habían enriquecido con el tráfico de esclavos, ya que "los pueblos que vocean la crueldad de los españoles" son "los mismos que van a las costas de África [y] compran animales racionales de ambos sexos" ${ }^{\prime 31}$. El conquistador de México ocupa un espacio especial a lo largo de esta carta. Las palabras del militar gaditano dibujan en toda la extensión de la palabra el carácter de un héroe: un ejemplo de arrojo y valor ante una empresa que llevó a cabo junto con "un puñado de hombres tan corto, que no se sabe cómo se ha de llamar"32. Cortés había sido un ejemplo de orden, disciplina militar y humanidad, prototipo de subordinación, valentía, coraje y determinación. En su texto, el de Medellín simbolizaba los efectos providenciales del imperio, de la civilización y de toda la "ventura" que España había aportado a América. Los extranjeros, sin embargo, habían deformado sus acciones y habían falseado los verdaderos rasgos de su carácter.

Ya en plena Guerra de los Pirineos, Juan Jiménez Donoso dotaría a Hernán Cortés de renovado protagonismo, como también había hecho Cadalso. Jiménez Donoso quiso imprimir su texto con el objetivo de instruir a los jóvenes soldados. El autor había alcanzado el cargo de teniente coronel de infantería del cuerpo de ingenieros. Su texto, distribuido en cinco volúmenes, iba dirigido a aquellos que habían decidido iniciarse en la carrera de las armas y tenía por título Despertador o avisos para la instrucción de la juventud militar ${ }^{33}$.

Además del conocimiento del noble arte de la guerra y el modelado de las conductas, Jiménez Donoso recogía las estratagemas y obligaciones de los militares en un texto con el que pretendía ilustrar a los soldados mediante conocimientos filosóficos, matemáticos, históricos y políticos. El autor conocía bien el terreno en el que se

\footnotetext{
Martínez Mata, 2000.

Cañas Murillo, 2016; Camarero Cea, 2000.

Cadalso, 1796: 33-41 y 182

Ibídem: 33-40.

Jiménez Donoso, 1794.
} 
aventuraba. Había estudiado en la Academia Militar de Barcelona - una de las instituciones que mejor representaban la modernidad científica en aquel momento, en la que también se habían formado Félix de Azara y otros compañeros-y realizado un proyecto general de fortificación en América, en concreto en la ciudad de Cartagena de Indias ${ }^{34}$. El teniente Jiménez Donoso iba a participar, además, en la pacificación de la provincia del Darién, así como en diversos reconocimientos territoriales en América $^{35}$.

De su texto hemos podido saber que se imprimieron más de 1500 ejemplares, una cifra nada desdeñable para la época ${ }^{36}$. En la obra, repasaba la importancia de que la tropa conociera la geografía, los idiomas y el pasado; sus modelos a imitar, por supuesto. Cortés era, a ojos de Jiménez Donoso, un personaje admirable y una especie de padre del ejército y "del soldado, amigo verdadero", capaz de mostrar, además, un afecto verdaderamente entrañable por sus compañeros de armas. Este héroe sublime evocado por Jiménez Donoso encajaba perfectamente con el discurso oficial sobre América que promovían las instituciones y por supuesto, con el conjunto literario de la épica dieciochesca, al lado de otros textos como los de Francisco Ruiz de León (1755), la apología de Vaca Guzmán (1778) premiada por la Real Academia, la vindicación de Nicolás Fernández de Moratín, Juan de Escoiquiz (1798), e incluso la obra más tardía de Pedro de Montengón (1820), todas ellas ya estudiadas por la historiografía especializada ${ }^{37}$.

Otras miradas castrenses continuaron construyendo la memoria cultural del héroe, otorgándole fama y reforzando su perfil de conquistador y excelente hombre de guerra a la par que humano. El conde de Noroña, Gaspar María de Nava (1760-1815) fue otro de aquellos hombres que guardaba memoria de sus grandes hazañas bélicas $\mathrm{y}$, en especial, de sus victorias. El coronel castellonense había ascendido rápidamente en la carrera de las armas. Entre sus campañas, había participado en el asedio de Gibraltar (1779-1783) -aquel en el que Cadalso encontró la muerte- y en la Guerra del Rosellón (1793-1795). Como el militar José de Alcedo, intervino también en la Guerra contra Napoleón (1808-1814), luchando en tierras gallegas. Durante aquellos años, como tantos otros hombres de armas, compaginó su interés por la política y la diplomacia con su afición a la poesía y a las letras. En algunos de sus versos, el conde de Noroña reflexiona sobre la muerte, el hombre, la razón y otros temas clásicos de la literatura dieciochesca.

El mariscal de campo escribió algunas palabras contra los desastres de la guerra, recordando los sangrientos laureles que habían coronado a Julio César, y manifestando su crítica al primero que "destrozando las sagradas leyes de la naturaleza, quiso osado elevar su cabeza con orgullo sobre todos los otros sus iguales" 38 . Gaspar María de Nava reconocía al comienzo de sus versos que muchas de aquellas líneas que escribía eran fruto de sus pasiones más vivas, sentimientos de rabia y alegría. Comprendía perfectamente -como Jovellanos y tantos otros ilustrados en aquellas décadas- la importancia de aprender la historia nacional. Su visión de la historia de España se hallaba muy unida a los valores militares, a las grandes batallas y con-

\footnotetext{
34 Capel - García - Moncada, 1983: 239. Jiménez obtuvo el proyecto para la construcción de un palacio destinado a residencia de los virreyes en Nueva Granada (Bogotá) que al final no se llevó a cabo. Marco Dorta, 1949.

Eduardo Rodríguez, 2014.

Barrena - Blas - Carrete - Medrano, 2004: 119-354.

Dowling, 1976; Fabbri, 1980 y 1984.

Noroña, 1799: 165.
} 
quistas del pasado, entre ellas las acontecidas en Numancia y Sagunto ${ }^{39}$. El escritor dedicó una importante composición literaria a la batalla de Trullás, en la que las tropas del general aragonés Antonio Ricardos (1727-1794) habían conseguido someter a las del militar francés Auguste Dagobert. En sus líneas resonaban también, por supuesto, los ecos pasados y el conocimiento de la célebre batalla de Otumba tras la derrota de la Noche Triste ${ }^{40}$.

La singularidad de aquel hombre irrepetible que había hecho caer un imperio fue, como vamos comprobando, uno de los grandes hilos conductores de la identidad de los militares españoles del siglo XVIII. Un ejemplo más puede brindárnoslo el cordobés Dionisio Alcalá Galiano (1760-1805), capitán de navío de la armada, estudioso y protagonista de diversas expediciones científicas. Profundamente interesado por las matemáticas y la astronomía, su trayectoria nos sitúa en el corazón de aquello que Antonio Lafuente y José Luis Peset han denominado la "militarización de la ciencia española"41. Con sólo quince años, el joven Dionisio ya había obtenido la plaza de guardiamarina en Cádiz. Tanto él como Vargas Ponce fueron instruidos en la prestigiosa Escuela de Guardia Marinas de Cádiz por el cartógrafo Vicente Tofiño de San Miguel ${ }^{42}$. Alcalá Galiano había participado en la expedición del estrecho de Magallanes y se había puesto a las órdenes del italiano Alejandro Malaspina. Murió mientras participaba en la Batalla de Trafalgar. Dionisio Alcalá Galiano participó, además, en el reconocimiento y el estudio del estrecho de Juan de Fuca, en Vancouver, fundamental desde el punto de vista político, geográfico y comercial ${ }^{43}$.

La Relación del viaje para reconocer el estrecho de Fuca (1802) fue impresa por orden del marino José Espinosa y Tello, incluyendo las experiencias del viaje. El objetivo era completar la observación del terreno y elaborar mapas de todos sus puertos e islas, determinando sus límites ${ }^{44}$. Alcalá Galiano tuvo ocasión de rememorar los tiempos de la conquista mexicana, y al héroe de Medellín como su principal artífice. El extremeño había sido un hombre poco común y en extremo valiente; alguien a quien ningún temor amedrentó jamás. Pero también había sido un individuo solidario y generoso, siempre dispuesto a socorrer a los demás. Su ánimo en las expediciones que dirigió permitía descubrir "el carácter grande y constante de un héroe" rino Alcalá Galiano recordaba vivamente el éxito de sus expediciones y consideraba que su historia era, en sí misma, la "verdadera apología de una nación"46.

La serenidad y la constancia habían sido algunas de las principales virtudes de Cortés: el caudillo que socorría a otros en situaciones críticas, el hombre íntegro que no "desmayaba ante tantos gastos y dificultades" ${ }^{47}$. El expedicionario había bebido en las Décadas de Antonio de Herrera para componer su texto. Sabía que muchos habían envidiado al conquistador, hasta el punto de llegar a sentir cierta animadver-

\footnotetext{
39 Ibídem: 153.

40 Ibídem: 1799: 169. Los versos fueron reproducidos también en un ejemplar del Memorial Literario, IV-1796, 69.

$41 \quad$ Lafuente - Peset, 1985.

42 Ródenas Valero, 2015: 82. Sobre esta cuestión puede consultarse Giménez López, 2006.

43 Las goletas destinadas para la expedición saldrían "desde el puerto de Acapulco, para adentrarse desde Fuca hasta San Francisco. Las instrucciones venían dadas por Floridablanca a través del conde de Revillagigedo". Sampedro Sánchez, 2013: 239.

44 Ibídem: 238.

45 Alcalá Galiano, 1802: XXVI.

46 Ibídem: XXII.

47 Ibídem: XXI.
} 
sión hacia él. Sus nombres se conservan todavía - sostenía- pero cualquiera de sus émulos era "digno de ser perpetuamente envuelto en las sombras del olvido"48. Dionisio Alcalá Galiano puso de relieve, además, un buen conocimiento de los textos críticos que ciertos autores extranjeros habían publicado sobre España. Su opinión al respecto era todo menos ambigua: "toda obra extranjera que trate de cosas nuestras debe leerse con circunspección y con desconfianza"49.

El entorno político de la corte continúa proporcionando abundantes testimonios del respeto y orgullo que muchos hombres del siglo sentían por la figura de Hernán Cortés. Es el caso del ministro de Carlos IV y la reina María Luisa de Parma, Francisco de Saavedra y Sangronis (1746-1819). Saavedra fue un militar, diplomático y funcionario que mantuvo estrecha relación epistolar con el escritor de la escuela poética salmantina León de Arroyal ${ }^{50}$. Saavedra había ingresado en el ejército a los 22 años: más o menos, hacia $1768^{51}$. Intervino en la creación de la Escuela Militar de Ávila (1773) y formó parte de la expedición española contra Argel junto a O’Reilly $(1775)^{52}$. Su carrera alcanzó la cima cuando en 1797 fue nombrado ministro de Hacienda. Francisco de Saavedra escribió a lo largo de su vida unos Diarios donde ofrecía sus visiones personales como político y viajero, sus experiencias en los lugares que había visitado en América -Luisiana, Jamaica, México y otros territorios- así como sus contactos y relaciones con el mundo religioso y civil. En una de las páginas de los Diarios afirmaba con claridad que sentía veneración por Hernán Cortés. No se le escapaba el significado del valle de Otumba (1520), batalla decisiva cuyo resultado recordaba perfectamente. Pese al paso del tiempo, Saavedra consideraba que su memoria debía eternizarse en piedra ${ }^{53}$.

Los textos del marqués de la Solana (1769-1808), capitán general de Andalucía, también deben ser tomados en consideración. Tras una excelente carrera militar en Argel -como el propio Francisco Saavedra había demostrado-participó en la Guerra del Rosellón y en Trafalgar. Su título de marqués adornaba, la identidad de Francisco Solano y Ortiz de Rozas, que había contraído matrimonio con la marquesa de Solana. Terminó sus días asesinado en 1808 en Cádiz, por un tumulto enfurecido que le acusaba de afrancesado. Los Solano tenían, en realidad, orígenes extremeños. De Zorita en la provincia de Cáceres, pasaron a Venezuela, para después ser ascendidos a marqueses del Socorro ${ }^{54}$.

Francisco Solano estaba preparado para poner en marcha una operación militar en Marruecos, hacia cuyos naturales sentía una profunda animadversión. Hacia julio de 1804, sin embargo, el monarca Carlos IV ordenó paralizar las operaciones previs-

48 Ibídem: $\mathrm{X}$.

49 Ibídem: CLXI.

50 Entre el grupo de poetas radicados en la universidad salmantina estuvieron Cadalso, Meléndez Valdés e Iglesias de la Casa, entre otros literatos, filósofos y gramáticos.

51 Morales Padrón, 2004: 11.

52 Ocupaba entonces el empleo de Ayudante mayor del Regimiento de Saboya. Véase el manuscrito Expedición contra Arjel (sic), ejecutada por el mes de junio de 1775, bajo las órdenes de los generales Conde de O'Reilly y don Pedro de Castejón, de exército y marina. 30-VI-1775. Biblioteca del Real Colegio del Corpus Christi de Valencia [Èspaña] (en adelante BRCCCV). Sign. BH / 217 / M-18, pp. s/n.

53 “Anduvimos diez leguas. A las 10 de la mañana llegamos a una pequeña elevación desde donde se descubre la llanura de Otumba, donde Cortés ganó la famosa batalla que le hizo dueño del imperio mexicano. No hay en todos aquellos redores monumento alguno que conserve la memoria de tan señalada acción”. [...]. En otro momento afirma en sus diarios "se ve el sepulcro de Hernán Cortés, que me infundió una especie de veneración". Morales Padrón, 2004: 245.

54 Alonso de Cadenas - Barredo de Valenzuela, 2002: 125. 
tas, que no llegaron a consumarse. El marqués de Solana quiso recordar entonces sus orígenes familiares extremeños, para afirmar que por sus venas corría la sangre de los conquistadores y que no podía olvidar a Hernán Cortés, aquel hombre que había conquistado un imperio, su energía y valentía. Solana había sido requerido para ayudar con tropas con el objetivo derrocar al emperador de Marruecos, Muley Solimán, que finalmente fracasó tras el viaje de espionaje de Domingo Badía. Son conocidos los planes de Godoy sobre la colonización en Marruecos (1802-1805) en una zona de claro interés comercial para España ${ }^{55}$. El propio emperador Muley Solimán era comparado por aquel entonces al emperador mexicano Moctezuma ${ }^{56}$.

Aunque por sus venas no corriera sangre extremeña, José Vargas Ponce también admiraba al marqués de Oaxaca. El escritor y marino gaditano (1760-1821) compaginó sus labores militares con una gran actividad literaria, en especial, con la traducción de textos extranjeros, como tantos otros compañeros. Vargas Ponce, además, solía dejarse ver por las mejores tertulias madrileñas. Fue miembro de la misma generación que Martín Fernández de Navarrete, a quien le unía una estrecha amistad. Relaciones estrechas compartió también, aunque de manera efímera, con Jovellanos y con el autor de las Cartas Marruecas, a quien al parecer admiraba personalmente ${ }^{57}$.

Durante su participación en las sesiones de las Cortes de Cádiz dejó un pequeño rastro de su admiración por el conquistador, a quien veía como "hombre discreto, valiente y conquistador de Nueva España" 58 . Como es sabido, a José Vargas Ponce se le había encomendado en 1792 la redacción de una historia de la marina española. Fueron ingentes las cantidades de textos que recopiló y los proyectos en los que se embarcó a lo largo de su vida. Entre las tareas que concentraron su atención estuvo la redacción de un texto sobre el viaje al estrecho de Magallanes, como haría el propio Dionisio Alcalá Galiano en el estrecho de Fuca.

Vargas Ponce es un buen ejemplo del encendido patriotismo del momento, de las apologías que exaltaban la historia, el gobierno y la literatura de España frente a las críticas extranjeras, entendiendo estas como el "desagravio que pide una madre común, la nación entera, la España misma" ${ }^{59}$. En su opinión, los españoles no debían dejar de salir en la defensa de sus propias aportaciones al acervo universal europeo, atacadas por los extranjeros. Y así lo hizo. El gaditano conocía bien la valoración negativa que muchos europeos habían hecho de la conquista americana -la despoblación, por ejemplo, las acusaciones de crueldad y muertes a manos de los conquistadores- pero, para juzgarla en todas sus restantes facetas, no debía dejar de subrayarse que en aquella gran empresa había participado alguno de los héroes más esclarecidos de la historia moderna, un hombre de grandioso carácter, una "estrella" de primera magnitud en el "firmamento" de España. Destinado al mundo de las academias que frecuentaba, compuso y pronunció varias conferencias, entre ellas el Discurso para entregar la Dirección de la Real Academia de la Historia desde Sevilla, el 27 de febrero de 1817. En este discurso mostró su admiración por el marqués de Oaxaca.

Vargas compartió con su admirado Cadalso la percepción heroica del conquistador de México y reclamó la producción de textos biográficos que sirvieran de ejemplo a sus paisanos. El autor consideraba una injusticia todos los problemas y con-

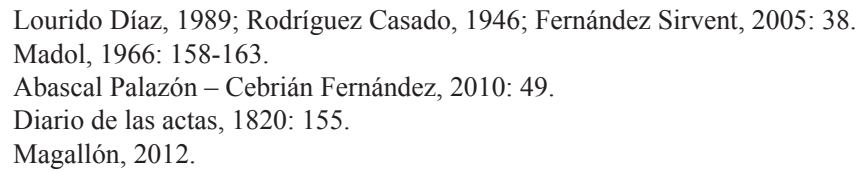


tratiempos que Cortés había tenido que sufrir a lo largo de su dilatada vida. Añadió que, tras el fallecimiento del marqués y durante muchos años, quienes visitaban el lugar en el que había pasado sus últimos días, se llevaban algunos fragmentos de su aposento como si de reliquias se tratase. El poder de atracción de Cortés era, en este sentido, enorme. No sólo la población visitaba la casa en la que había nacido el conquistador, como había hecho Bowles. El lugar en el que murió el héroe de Medellín también se convirtió en un famoso espacio de peregrinación. Nos hallaríamos, sin duda, ante la percepción o la constatación de cierta dimensión sacra adquirida por el conquistador ${ }^{60}$.

Fueron muchos los oficiales que conocieron y valoraron positivamente las acciones de Hernán Cortés en América. Algunos sintieron admiración por el extremeño, otros agrandaron su memoria, su mito, su heroicidad y su dimensión guerrera; e, incluso, justificaron sus propios comportamientos políticos con su recuerdo, como hizo el marqués de Solana. La necesidad de erigir estatuas a los héroes militares y en concreto, a la figura del marqués de Oaxaca, estuvo bien presente a lo largo de la centuria, y no sólo desde el punto de vista estrictamente militar. Así lo atestiguan las palabras de Clemente Peñalosa y Zúñiga, capellán y arcediano de la Iglesia de Segovia, en su impreso "El honor militar" $(1795)^{61}$.

Los textos compuestos por estos hombres, tanto peninsulares como criollos, que ensalzaban los valores militares -Olmeda, Alcedo, Arroyal, Cadalso, Jiménez Donoso, el conde de Noroña, Alcalá Galiano, Saavedra, el marqués de la Solana y Vargas Ponce- compartieron un mismo sesgo cronológico, una formación similar, unas expediciones y batallas comunes, e incluso relaciones de amistad. Muchas eran, sin embargo, las diferencias que les distanciaban y los propósitos que habían motivado su escritura, pero todos ellos utilizaron las acciones memorables del pasado -las hazañas de la conquista de México personalizadas en Cortés- para fundamentar y legitimar sus discursos. Sus aportaciones son un índice claro de la notable popularidad militar de Hernán Cortés hacia finales de siglo y de cierto acervo cultural común, una cultura histórica compartida, que había ido gestándose con el tiempo. La formidable contribución de los militares de finales de siglo en la construcción del perfil histórico del personaje no puede dejar de subrayarse. Su tono fue, como hemos visto, marcadamente vindicativo. La elaboración de sus contornos no se alejará demasiado del amplio proceso de heroización que ya circulaba en otros medios, tales como crónicas, compendios históricos y traducciones, dirigidos a un público muy amplio, infantil y adulto, de la imagen oficial de América que estaban ayudando a difundir la Corona e instituciones como la Real Academia de la Historia y de la Lengua ${ }^{62}$.

60 "Durante muchos años quienes viajaban a Sevilla visitaban aquel pueblo, llevando como reliquias pedacitos del aposento donde finó.” Discurso de José Vargas Ponce. Discurso para entregar la dirección de la Real Academia de la Historia desde Sevilla. Sevilla, 27-II-1817. Real Academia de la Historia [España] (en adelante RAH). RAH-9-6052-5, ff.10r-10v. Real Academia de la Historia [España] (en adelante RAH). RAH-9-6052-5. La documentación puede consultarse en Abascal Palazón - Cebrián Fernández, 2010: 405.

${ }^{61}$ Peñalosa Zúñiga, 1795: 48-49. Peñalosa recordaba las hazañas de los antiguos nobles y los túmulos de los valientes guerreros que habían salvado la patria, la gloria que las generaciones del pasado habían legado al presente. En su opinión, Hernán Cortés -y Pizarro, también- era un claro merecedor de, al menos, una estatua, por representar con claridad la más absoluta generosidad, valentía, intrepidez y justicia. El conquistador era, en esencia, un estímulo a la conducta para las generaciones del presente.

62 Los ejemplos de los fuertes vínculos que subyacían entre la conquista de América y la reputación de la nación española no sólo se vislumbran en la convocatoria del premio literario auspiciado por la Real Academia y la escritura de las crónicas de Salazar y Solís. La traducción que Tomás de Iriarte realizó de la obra del ilustrado ale- 
Aquellos intelectuales que pretendieron enfatizar su dimensión militar, grandeza y singularidad - espoleados de una manera muy intensa por las frecuentes coyunturas bélicas que atenazaron al país entre 1775 y 1814 y la incidencia de la polémica sobre América- veneraron su memoria y, bajo estilos y fórmulas bien distintas, trataron de cultivar el reconocimiento público y la popularidad de Cortés. Así pues, el personaje se impregna de valores, experiencias subjetivas y metáforas con las que se identifican sus hazañas y personalidad. Como hemos visto, la figura del extremeño sedujo a muchos hombres de armas e invitó a la acción política a no pocos, resultado de una actividad literaria y política prolongada en el tiempo, de unas decisiones, unas escrituras, unas apropiaciones. Entender y explicar de qué manera fascinó el personaje a los individuos de la Ilustración y por qué su mito, harto repetido, tuvo cierta eficacia ideológica es, sin duda, un asunto complejo. En cualquier caso, los usos públicos del personaje en la crisis del Antiguo Régimen albergan una gran potencialidad. Desde una marcada dimensión política, se vinculan estrechamente con los conceptos de nación, imperio y guerra, como pilares en los que se sostiene su memoria cultural.

\section{Reflexiones finales}

El análisis de este abanico de textos, más que apuntar hacia cierto grado de "militarización" ${ }^{63}$ dentro del tejido social de aquel momento, permite comprobar la persistencia de unos valores bélicos que, vinculándose a través de la figura del conquistador, se reafirman y se ensalzan a través de la literatura y la historia. Quizá porque éstos, como las ideas, corren el riesgo de perderse -aunque cuenten con el apoyo explícito de la Corona- si no se ratifican y repiten cotidianamente. En este sentido el propio Hernán Cortés, revestido de cierta aureola de popularidad, fue una herramienta más que la Corona, los militares y los publicistas no desaprovecharon.

Una gran parte, por no decir toda, de la literatura cortesiana reelaborará diversos materiales del Renacimiento -crónicas, relaciones, etc.- que se adaptan, ahora, a nuevos fines, nuevos tiempos y nuevos significados. El estudio de estos valores ensalzados -que giran, como hemos visto, en torno a la patria, lo militar, el poder y la religión- permiten realizar una comparación entre diversas coyunturas y periodos como son el siglo XVI y el siglo XVIII, a saber, sus puntos en común, sus paralelismos y diferentes evoluciones. Tanto en una cronología como en otra, una parte del éxito del mito cortesiano radicó, con toda seguridad, en la enorme cantidad de

mán Joachim Heinrich Campe, constituye un buen exponente de esta relación de éxito. Dedicado especialmente al público infantil, en sus páginas refulgían con fuerza las figuras individuales de la conquista, principalmente Colón, Cortés y Pizarro. Corradi, 1803. Los compendios, especialmente dirigidos a los jóvenes y de carácter histórico, como el del padre Francisco Cárdenas de la Concepción y el clérigo Francisco Vázquez, encontraban un pequeño espacio para retratar a Cortés como varón intrépido y heroico, "de notable esfuerzo y penetración". Cárdenas de la Concepción, 1799: 136-137; Vázquez, 1807: 146.

63 La cuestión de la militarización de la sociedad de Antiguo Régimen es compleja y delicada. Pablo Fernández Albadalejo ha negado la posibilidad de militarización de la sociedad española antes de finales del s. XVIII. Fernández Albadalejo lo entiende como un fenómeno inseparable del momento revolucionario de 1808 frente a aquellos historiadores que lo han relacionado con el establecimiento de la dinastía de los Borbones. Pese a ello -y como subraya Juan Francisco Pardo Molero- no debe olvidarse que desde el siglo XVI la importancia y la presencia de lo militar aumentan en la esfera de lo social y cultural. Lo militar no sería, sin embargo, un elemento predominante en la sociedad, sino que más bien muchos textos tenderán a subrayar aquello que de militar tenía la sociedad desde la Edad Media. Pardo Molero, 2004 y 2010; Fernández Albadalejo, 1998. 
significantes que llegó a concitar y en el elevado número de conceptos -necesarios para la época, sin duda- de los que su figura quedó recubierta.

En ocasiones, y como ha podido comprobarse, una pequeña y tímida referencia a Hernán Cortés podía evocar un recuerdo más amplio y extenso. Otras veces, se introducía un largo panegírico más detallado, con una intención marcadamente moralizante, patriótica, ejemplarizante e instructiva. Militares de diferente graduación, del mundo de la oficialidad -y también otros autores de la esfera religiosa y política, que ensalzaban vehementemente los valores militares- escribieron referencias más o menos extensas, mencionando al marqués de Oaxaca como excelente hombre de armas, figura heroica y humana, el más aguerrido y esforzado guerrero al servicio de aquel presente. Cabe entender estos textos, concebidos para ser publicados, en su mayoría, dentro de sus propios entornos sociales y políticos, en un contexto bélico y de crisis del Antiguo Régimen, también plagados de sentimientos y emociones, aquellos suscitados por el hecho de sentirse "víctimas" de la propaganda adversa contra España por su actuación colonial en América.

Estas imágenes canónicas del pasado iban encaminadas a la justificación de las operaciones militares en el presente y a legitimar a la propia comunidad militar, describen sus características y sus valores como grupo social, dotan al ejército de cohesión y orgullo. Son imágenes que juegan un rol importante en la construcción de la identidad nacional, aquella que se sustenta en una cultura histórica común, en una imagen del pasado compartida, con un referente sentido y recordado en forma de modelo, de héroe guerrero ${ }^{64}$. En otras palabras, en esta literatura puede rastrearse todo un depósito de mitos coherentes, de gran valor moral y político, que se transmiten a gran escala desde el mundo literario y político. La relación con el pasado que establece una sociedad determinada siempre es necesaria para construir su propia identidad colectiva, tejida, al mismo tiempo, con otras más amplias. Hernán Cortés puede interpretarse, en este sentido, como un exponente clave del imaginario en el que se moverá una parte importante de este grupo social.

La necesidad de responder a las críticas europeas, la noción de patria, la participación en batallas, viajes y expediciones, su propia amistad personal, las lecturas comunes -la crónica de Solís, por ejemplo- y la correspondencia privada generaban afinidades entre unos y otros hombres de armas. Como hemos visto, el asedio de Gibraltar fue uno de los episodios bélicos en el que muchos de ellos coincidieron. Fue un grupo muy diverso: hombres polifacéticos, que desempeñaron cargos importantes en la sociedad de la época, en el mundo científico, matemático y geográfico, que estuvieron cerca de la corte y se relacionaron con el movimiento académico, academias de letras y Reales Sociedades. Pese a sus diferencias, su percepción sobre Hernán Cortés, al menos oficialmente, fue sin duda un elemento de afinidad y solidaridad, un punto en común además de muchos otros. En efecto, Hernán Cortés brindaba una oportunidad excelente para sublimar la capacidad de combate de las tropas españolas, su fortaleza y unión, su sacrificio, así como la de educar a los jóvenes militares - como hizo Jiménez Donoso- que deseaban iniciarse en el ejército, y reivindicar - hasta cierto punto, al menos- un fenómeno tan destructor como indispensable para los estados modernos.

La instrumentalización política de Hernán Cortés sirvió para legitimar la imagen de la monarquía española, dañada entre la opinión pública europea, pero al mismo

64 Sánchez Costa, 2009; Sánchez Marcos, 1998; Woolf, 2003; Assmann, 2011. 
tiempo otorgaba cierto sentido y potencialidad a los militares como grupo, si es que podemos hablar de un grupo, por supuesto, con sus matices y diferenciaciones, en ocasiones muy marcadas. La dimensión militar de Hernán Cortés no sólo fue impulsada, por supuesto, por el ejército borbónico a través de la imprenta. Su sombra se proyectó también en sermones pronunciados por los clérigos y en los artículos de la prensa periódica ${ }^{65}$.

En otro sentido, el estudio de esta literatura heterogénea permite reflexionar sobre la cuestión de que hasta qué punto los hombres y mujeres de la Ilustración estaban embebidos de una "cultura bélica" que, quizás, resultaba tanto más necesaria cuanto la monarquía española estaba perdiendo su papel preponderante en el concierto político y estratégico internacional en aquel momento histórico. Conviene, por tanto, que, en la interpretación de estos fragmentos textuales no se desatiendan los complejos nexos entre la Ilustración y los discursos de la guerra, la violencia, el honor y el poder, aquellos relatos del universo bélico que se infiltran hasta lo más profundo, lo más cotidiano y lo más íntimo de las vidas de los individuos.

La lectura militar de Hernán Cortés, en síntesis, alcanzó una elevada importancia en este contexto particular frente a otras coyunturas históricas del siglo anterior, en el que los hombres eran conscientes de que tenían un pasado a sus espaldas que les condicionaba, que marcaba su presente y que podía ayudarles a actuar. El Hernán Cortés de este momento histórico surge al calor de la guerra -y por supuesto, también al compás de la polémica sobre el "Nuevo Mundo"66- y es capaz de hacer sentir a los españoles del crítico comienzo del siglo XIX como diferentes, valientes, victoriosos y gloriosos: de emprender lo más difícil y resolver con éxito lo impensable. En efecto, estas lecturas del conquistador no sólo son un contundente ejemplo del peso del pasado sobre el presente, sino también del peso del presente sobre el pasado. Así lo demuestra un texto anónimo que había salido de la imprenta valenciana de Orga en 1808. En él, Hernán Cortés se convierte en un mito potencialmente conmovedor del ánimo de la resistencia militar. Cuatro páginas cargadas de retórica sentimental y fuerza dramática en el que el personaje resucitaba literalmente. El marqués volvía a la vida esta vez con la intención de incitar a la violencia contra los enemigos franceses. Se sumaba, así pues, a la lista de individuos capaces de levantar en armas a aquellos que luchaban contra Napoleón Bonaparte ${ }^{67}$.

Podría plantearse el lector si los militares dieciochescos - muchos de ellos oficiales y veteranos del ejército- se sintieron vulnerables, débiles o no suficientemente respaldados por el Estado, de modo que las alusiones al "mítico" Cortés eran un mecanismo destinado a elevar la moral colectiva o si, por el contario, lo único que

65 Según unas breves líneas del Memorial literario, en las páginas dedicadas a la traducción del compendio del escritor alemán Joaquim Heinrich Campe (1746-1818), Hernán Cortés había nacido "pobre y desvalido, padeció grandes persecuciones y fue probado en toda suerte de adversidades, debiendo sólo a su talento y a su ánimo el llegar a ser del corto número de grandes hombres que los tiempos modernos pueden oponer a los antiguos". Memorial literario, $\mathrm{n}^{\circ}$ 51, 1804, 185. También el Diario de Madrid se sumó a la exaltación del personaje, a medio camino entre la divinidad humanizada y la heroicidad del gran caudillo moderno. Diario de Madrid, $\mathrm{n}^{\circ}$ 144, 24-V-1790, 575. La oratoria religiosa rindió reconocimiento y adhesión al conquistador de México. Así lo prueban, entre otros, los sermones del obispo liberal Antonio Posada Rubín de Celis, cuyo discurso fue editado gracias al apoyo del Consejo de Guerra. Posada Rubín de Celis, 1804: 33-36.

${ }_{66}$ No forma parte de mis objetivos en este momento abordar una problemática ampliamente trabajada y de larga tradición historiográfica. Unos pocos ejemplos en: Gerbi, 1960; Sebastiani, 2011; Pagden, 1991; Cañizares Esguerra, 2007.

67 Discurso, 1808: 24. 
pretendían era responder a los ataques que trataron de desdibujar o degradar su presunta grandeza. Su ejemplo resultaba útil, de todos modos, para justificar, alentar o contraponer conflictos militares y tipos diversos de violencia, para construir un estereotipo que legitimara la lucha contra el enemigo político y religioso, para instruir al soldado, presentándole un modelo unívoco que imitar. Cabe resaltar, finalmente, la sintonía del personaje con el culto y el amor a la patria, con su impreciso significado territorial, emocional y al mismo tiempo político, con una patria que se sacraliza en las contiendas y en la literatura religiosa a través del ideal pro patria mori ${ }^{68}$.

¿Pudo convertirse entonces Cortés en una figura de devoción compartida? Desde luego, el personaje recibió cierto culto, una admiración que nos ha permitido reconstruir algunas redes de identidades colectivas - profesionales, nacionales, etc.- un elevado grado de adhesión en el contexto de las guerras contra la Convención y de la Independencia. Entre las razones de su éxito se hallaba, sin duda, la capacidad de adaptación del personaje: su versatilidad para representar los valores de la cultura y del imperio español, su enorme popularidad frente a otros conquistadores del "Nuevo Mundo" y la cantidad de actores sociales implicados en la activación de su memoria.

\section{Referencias bibliográficas}

Abascal Palazón, Juan Manuel - Cebrián Fernández, Rosario. José Vargas Ponce (17601821) en la Real Academia de la Historia. Madrid: Publicaciones de la Real Academia de la Historia, 2010.

Alcalá Galiano, Dionisio. Relación del viage hecho por las goletas sutil y mexicana en el año de 1792 para reconocer el estrecho de Fuca. Madrid: Imprenta Real, 1802.

Alcedo, Antonio. Diccionario geográfico-histórico de las Indias Occidentales o América. Madrid: Imprenta de Manuel González, 1789.

Alonso de Cadenas, Ampelio - Barredo de Valenzuela, Alfonso. Nobiliario de Extremadura. Madrid: Instituto Salazar y Castro, Ediciones de la Revista, 2002.

Andújar, Francisco. Los militares en la España del siglo XVIII: un estudio social. Granada: Universidad de Granada, 1991.

Arroyal, León. Las odas. Madrid: Joaquín Ibarra, 1784.

Assmann, Aleida. Cultural memory and western civilization. Functions, Media, Archives. Cambridge: Cambridge University Press, 2011.

Barrena, Celemente - Blas, Javier - Carrete, Juan - Medrano, José Miguel. Calcografía nacional. Catálogo general. Madrid: Real Academia de Bellas Artes de San Fernando Calcografía Nacional, 2004.

Bowles, Guillermo. Introducción a la Historia Natural y Geografía física de España. Madrid: Imprenta Real, 1782.

Cadalso, José. Cartas Marruecas. Barcelona: Imprenta de Piferrer, 1796.

Camarero Cea, Manuel. "Composición y lectura de las Cartas Marruecas de Cadalso". Dieciocho. Hispanic Enlightenment, vol. 23, nº I (2000), 133-146.

68 El arranque histórico del "culto a la patria" puede situarse antes en el tiempo. Sobre el tópico "pro patria mori", de los soldados y su relación con la idea de cruzada religiosa y el rey en una época anterior puede consultarse Kantorowicz, 1985. Aquellos que mueren por la corona, la patria, la justicia y Dios en el campo de batalla serán coronados como mártires. El poder legitimador de este ideal tiene, como explica el autor, múltiples connotaciones. 
Cañas Murillo, Jesús. "Una inconfesa novela de la Ilustración: las Cartas Marruecas del Coronel Cadalso". Cuadernos de Ilustración y Romanticismo, no 22 (2016), 205-227.

Cañizares Esguerra, Jorge. Cómo escribir la historia del Nuevo Mundo: historiografías, epistemologías e identidades en el mundo del atlántico del siglo XVIII. México: FCE, 2007.

Capel, Horacio - García, Lourdes - Moncada, José Omar. Los ingenieros militares en España siglo XVIII. Repertorio biográfico e inventario de su labor cientifica y espacial. Barcelona: Publicaciones y Ediciones de la Universidad de Barcelona - Cátedra de Geografía Humana, Universidad de Barcelona, 1983.

Cárdenas de la Concepción, Francisco. Compendio de la Historia de España para la instrucción de los niños. Madrid: Imprenta de la Viuda de Marín, 1799.

Chávez, Thomas E. "Vender cara la victoria al enemigo: España, el escenario europeo y la independencia de los Estados Unidos". Espacio, Tiempo, Forma. Serie IV. Historia Moderna, $\mathrm{n}^{\circ} 14$ (2001), 545-562. DOI: 10. 5944/etfiv.14.2001.3417.

Checa Beltrán, José (coord). Lecturas del legado español en la Europa ilustrada. Madrid: Iberoamericana, Frankfurt Am Main, Vervuert, 2012.

Corradi, Juan. Descubrimiento y conquista de la América o Compendio de la Historia General del Nuevo Mundo. Madrid: Imprenta Real, 1803.

Diario de las actas. Diario de las actas y discusiones de las cortes. Legislatura años 1820 y 1821. Madrid: Imprenta Especial de las Cortes, 1820.

Discurso. Discurso pronunciado en estos días por un expectro de Hernán Cortés a los españoles. Valencia: Imprenta de Joseph de Orga, 1808.

Dowling, John. “A poet rewrites history: Nicolás Fernández de Moratín and the burning of Cortes's ships”. South Atlantic Bulletin, vol, 41, n 4 (1976), 66-73.

Eduardo Rodríguez, Nelson. "El imperio contraataca: las expediciones militares de Antonio Caballero y Góngora al Darién (1784-1790)". Historia Crítica, no 53 (2014), 201-223. DOI: 10.7440/histcrit53.2014.09.

Fabbri, Maurizio. "Las naves de Cortés destruidas en la épica española del siglo XVIII". Revista de literatura, vol. 42, nº 84 (1980), 53-74.

- Vagabondi, visionari, eroi. Appunti su testi "in minore” del Settecento spagnolo. Abano Terme: Piovan Editori, 1984.

Fernández Albadalejo, Pablo. "Soldados del rey, soldados de Dios": ethos militar y militarismo en la España del siglo XVIII". Espacio Tiempo y forma, Serie IV, Historia Moderna, vol. 11 (1998), 303-320. DOI: 10.5944/etfiv.11.1998.3369.

Fernández Santamaría, José Antonio. El Estado, la guerra y la paz. El pensamiento político español en el Renacimiento (1516-1559). Madrid: Editorial Akal, 1988.

Fernández Sirvent, Rafael. Francisco Amorós y los inicios de la educación física moderna. Alicante: Publicaciones Universidad de Alicante, 2005.

Forner, Juan Pablo. Pasatiempo de D. Juan Pablo Forner en respuesta a las objeciones que se han hecho a su oración apologética por la España. Madrid: Imprenta Real, 1787.

- Amor de la patria. Discurso que en la Junta general publica que celebró la Real Sociedad Económica de Sevilla, el 23 de noviembre de 1794. Sevilla: Imprenta de los Hijos de Hidalgo y González de la Bonilla, 1794.

García Hernán, David. La cultura de la guerra y el teatro del siglo de Oro. Madrid: Sílex, 2006.

García Hernán, David - Maffi, Davide. Guerra y sociedad en la Monarquía Hispánica: Política, estrategia y cultura en la Europa Moderna (1500-1700). Madrid: Laberinto Editores, CSIC, Fundación Mapfre, 2006. 
García Hurtado, Manuel Reyes. El arma de la palabra: los militares españoles y la cultura escrita en el siglo XVII (1707-1808). La Coruña: Servicio de Publicaciones, 2002.

Gerbi, Antonello. La disputa del Nuevo Mundo: historia de una polémica: 1750-1900. México: Fondo de Cultura Económica, 1960.

Gies, David. "De Medellín a Cholula. La figura de Hernán Cortés en el teatro español de los siglos XVIII y XIX”. En La representación de la Conquista en el teatro español desde la Ilustración hasta finales del Franquismo, editado por Floeck, Wilfried - Fritz, Sabine. Hildesheim: Georg Olms, 2009, 193-204.

Giménez López, Enrique. "La militarización de las ciencias útiles". Canelobre, Revista del Instituto Alicantino de Cultura Juan Gil Albert, no 51 (2006), 36-43.

Hernández, Bernat. "Una vindicación de la conquista en vísperas de las emancipaciones: Hernán Cortés según el abate Ramón Diosdado Caballero". En Tierras prometidas: de la colonia a la independencia, editado por Castany, Bernat. Madrid - Bellaterra: Centro para la Edición de los Clásicos Españoles - Universitat Autònoma de Barcelona, 2012, 131-152.

Herrero Rubio, Alejandro. Internacionalistas españoles del siglo XVIII, D. Joseph Olmeda y León. Valladolid: Publicaciones del Seminario de Estudios Internacionales Vázquez de Menchaca, 1947.

Hidalgo Nuchera, Patricio. "Los EEUU en el Diccionario de Alcedo: propaganda, información e ilustración". REDEN: Revista española de estudios norteamericanos, $\mathrm{n}^{\mathrm{0}}$ 15-16 (1998), 183-194.

Jiménez Donoso, Juan. Despertador o avisos para la instrucción de la juventud militar en el rompimiento de una guerra. Madrid: Imprenta Real, 1794.

Kantorowicz, Ernst. Los dos cuerpos del rey. Un estudio de teología política medieval. Madrid: Alianza, 1985.

Lafuente, Antonio - Peset, José Luis. "Militarización de las actividades científicas en la España ilustrada". En La ciencia moderna y el conocimiento del Nuevo Mundo, editado por Peset, José Luis. Madrid: Consejo Superior de Investigaciones Científicas - Sociedad Latinoamericana de Historia de las Ciencias y de la Tecnología, 1985, 127-147.

Lavenia, Vincenzo. "El soldado cristiano y su capellán. Disciplina de la guerra y catequesis en la temprana edad moderna". En Formas de control y disciplinamiento. Chile, América y Europa, siglos XVI-XIX, editado por Undurraga, Verónica - Gaune, Rafael. Santiago de Chile: Uqbar Editores, 2014a, 328-352.

- I catecismo dei soldati. Guerra e cura d'anime in età moderna. Bologna: Edizioni Dehoniane, 2014b.

Lerner, Isaías. "The diccionario of Antonio de Alcedo as a source of Enlightened ideas". En The Ibero-american Enlightenment, editado por Aldridge Owen, Alfred. Chicago - London: University of Illinois Press, 1971, 71-93.

Lourido Díaz, Ramón. Marruecos y el mundo exterior en la segunda mitad del siglo XVIII. Madrid: Agencia Española de Cooperación Internacional, 1989.

Madol, Hans. Godoy. El primer dictador de nuestro tiempo. Madrid: Alianza Editorial, 1966.

Magallón, Jesús Pérez. “Apologías, identidad nacional y desplazamiento de España a la periferia de la Europa Moderna”. En Lecturas del legado español en la Europa Ilustrada, editado por Checa Beltrán, José. Madrid - Frankfurt Am Main: Iberoamericana Vervuert, 2012, 13-40.

Marco Dorta, Enrique. "El palacio de los virreyes de Bogotá; un proyecto fracasado". Anales del Instituto de Arte Americano e Investigaciones Estéticas, no 2 (1949), 71-77.

Martínez de Hervás, Joseph. Elogio al excelentísimo señor D. Antonio Ricardos Carillo de Albornoz, capitán general de los Reales Ejércitos, leído en la Real Sociedad de Amigos 
del País de Madrid en la junta del 19 de septiembre de 1795. Madrid: Imprenta de Sancha, Impresor Real de la Sociedad, 1795.

Martínez Mata, Emilio. "El texto de las Cartas Marruecas de José de Cadalso". En Actas del XIII Congreso de la Asociación Internacional de Hispanistas, celebrado del 6 al 8 de julio de 1998, editado por Sevilla Arroyo, Florencio - Alvar, Carlos. Madrid: Editorial Castalia, 2000, 29-38.

Mestre, Antonio. Apología y crítica de España. Madrid: Marcial Pons Historia, 2003.

Morales, Andrés. "Visión de Hernán Cortés como personaje histórico y protagonista literario de la Hernandia, del novohispano Francisco Ruiz de León". En Rebeldes y aventureros: del Viejo al Nuevo Mundo Cortés, editado por Cortés, Hugo - Godoy, Eduardo - Insúa, Mariela. Pamplona: Editorial Iberoamericana, 2008, 188-193.

Morales Padrón, Francisco. Diario de D. Francisco de Saavedra. Sevilla: Secretariado de Publicaciones de la Universidad de Sevilla - Consejo Superior de Investigaciones Científicas, 2004.

Noroña, conde de. Poesías. Madrid: Imprenta de Vega y Compañía, 1799.

Olmeda y León, José. Elementos del derecho público, de la paz y de la guerra ilustrados con noticias históricas, leyes y doctrinas del derecho español. Madrid: Oficina de la Viuda de Manuel Fernández, 1771.

- Noticia de los premios distribuidos por la Real Sociedad Económica de Amigos del País de Madrid. Madrid: Joaquín Ibarra, 1783.

Pagden, Anthony. El imperialismo español y la imaginación política: estudios de teoría social y política europea e hispanoamericana (1513-1830). Barcelona: Planeta, 1991.

Pardo Molero, Juan Francisco. "Capitanes del Renacimiento: ética militar en la España mediterránea c. 1500-1550". Revista de Historia Moderna, Anales de la Universidad de Alicante, no 22 (2004), 87-106. DOI: 10.14198/rhm2004.22.

— "Hijos del Dios Marte. Historias de soldados y espíritu de cuerpo en los ejércitos de la monarquía hispánica”. Mediterranea Ricerche Storiche, vol. 7 (2010), 533-544.

Peñalosa y Zúñiga, Clemente. El honor militar. Causas de su origen, progresos y decadencia. Madrid: Imprenta Benito Cano, 1795.

Posada Rubín de Celis, Antonio. Discurso pronunciado en la Real Iglesia de San Isidro. Madrid: Imprenta Real, 1804.

Ródenas Valero, Almudena de la Caridad. “Arte y Ciencia: El Atlas Marítimo de España de Vicente Tofiño de San Miguel”. Imafronte, no 24 (2015), 73-102.

Rodríguez Casado, Vicente. Política marroquí de Carlos III. Madrid: Consejo Superior de Investigaciones Científicas, 1946.

Rubial García, Antonio. "De héroe a villano. La imagen de Hernán Cortés en el pasado de la independencia (1794-1824)". En 1810-1910: Reflexiones sobre dos procesos históricos, editado por Gómez Álvarez, Cristina - Mac Gregor Gárate, Josefina - Ozuna, Mariana. México: Facultad de Filosofía y Letras, Universidad Nacional Autónoma de México, 2010, 31-48.

Sampedro Sánchez, César. La marina española en las expediciones cientificas y militares del siglo XVIII. Una visión a través de la carrera del brigadier Dionisio Alcalá Galiano y Pinedo (1760-1805). Alicante: Universidad de Alicante, 2013.

Sánchez Costa, Fernando. "La cultura histórica: una aproximación diferente a la memoria colectiva". Pasado y memoria. Revista de Historia Contemporánea, no 8 (2009), 267-286. DOI: 10.14198/PASADO2009.8.12.

Sánchez Marcos, Fernando. "Notas sobre la cultura histórica en el siglo XVIII: el compendio del P. Buffier, manual en el colegio de Nobles de Cordellas". Pedralbes, Revista de Historia Moderna, $\mathrm{n}^{\circ}$ 8, fasc. 2 (1988), 245-254. 
Sebastiani, Silvia. "Las escrituras de la Historia del Nuevo Mundo: Clavíjero y Robertson en el contexto de la Ilustración Europea”. Historia y grafía, vol. 27 (2011), 203-236.

Solís, Antonio. Historia de la conquista de México. Madrid: Imprenta de Antonio de Sancha, 1783.

Vázquez, Francisco. Compendio de la Historia Universal o Pintura Histórica de todas las Naciones. Su origen, vicisitudes y progresos hasta nuestros dias. Madrid: Imprenta Real, 1807.

Woolf, Daniel, The social circulation of the past. English historical culture, 1500-1730. Oxford: Oxford University Press, 2003. 